\title{
Exploring the perceived security in transit: the Venetian students' perspective
}

\author{
Alessandra Libardo \& Silvio Nocera \\ IUAV University of Venice, Italy
}

\begin{abstract}
The current growing private travel demand generates high external costs and hence calls for effective solutions to be adequately managed. Unsustainable passenger modal choice is generally related to one of the following six factors: economic growth, increasing income levels, rising car ownership, transport system improvements, demographic changes and competition between public and private transport. Some of the latter effects will be examined in this paper. Massive use of private car may be induced from several reasons. Barring user irrationality, discontent with transit service should be considered between the main causes. This is normally caused from low perceived quality, and previous surveys indicate security between the parameters which influence transit quality judgment more intensively. This paper describes a survey conducted from the authors within the students of their institution through a SP questionnaire. Empirical findings are presented for a data set of 347 out of a total population of 5,738 (6.05\%). Drawn conclusions seem to indicate that a significant part of the respondents clearly exhibited fears for their personal security in relation to transit stops and immediate access routes. Not surprisingly, female respondents exhibited higher levels of fear than the males. Respondents generally tend to prefer transit stations that are guarded and spaces in which they feel that others could observe them through CCTV in operation (when approaching access points and while waiting on transit stops). Survey analysis has also allowed to determinate places and time slots in which the passenger security perception is higher and some measures to adopt in order to make this feeling stronger.

Keywords: public transport, safety perception, transit quality.
\end{abstract}




\section{Crime and fear of crime background}

Brantingham et al. [1] identify the means by which the transport mode can affect criminal opportunities. Firstly, persons tend to compare transit to car travels: the latter is predominantly "private" and is normally used by individuals or small groups, who are generally well-acquainted. The former involves large numbers of strangers, held together by common travel purposes for discrete periods of time. Transit crime risk is perceived at point of origin, during the journey itself and at the destination, and offenders have also greater numbers of potential victims from which to select. Secondly, transit supply is not uniform. The car is versatile and flexible while public transport has fixed schedules, clustering people at specific times, with varying but predictable densities. This makes the perceived crime risk highly mutable during the different time frames by both potential offenders and their victims. Thirdly, transit clusters destinations and travel paths differently. Private car users can move between an infinite number of potential destinations through many travel paths, while public transport users must enter and exit the system at a limited number of origins and destinations. Moreover, transit travel paths are defined, and their entrances are restricted. The location of potential victims and critical points is therefore known to the actual offenders. Finally, crime modality is different: car travel offenders must search for suitable, and preferably unguarded targets with rewards easy to be removed and easily transported. Public transport tends to facilitate crimes against the person generally where target density is very high or very low (e.g. pickpocketing and aggressions).

Research has attempted to measure the impact of a variety of potential "solutions" designed to reduce recorded crime rates in the railway environment. Studies have found that enhanced lighting [2] can reduce levels of fear. "Good" design was found to contribute to low crime on Hong Kong's Mass Transit System [3] and in Washington's Metro System [4]. More uniformed staff has been found to enhance security awareness [5], although CPTED and rapid maintenance and repair of any damage have more recently found to be effective in reducing crime rates and fear of crime [6]. A study by the Parliamentary Travel Safe Committee [7] in Brisbane (Australia), recommended a wide-range of measures to reduce crime and the fear of crime. However, Eck [8] reviews various studies of public transport and claims that little is currently known about the effectiveness of the different interventions. User-friendly location and operating modalities of the stops, and high service reliability of the operation are generally very appreciated from the customers [9].

Crucially, recorded crime statistics represent only a fraction of total crime: the missing data representing the "dark figure of crime" [10] that may not be witnessed or discovered, or remains either unreported or unrecorded - for a variety of complex reasons. Reluctance to delay one's journey, a lack of confidence that the offender will be apprehended, the absence of someone to actually report an incident to, and the belief that a reported incident will not be taken seriously are examples of non-reporting behavior. 
Clarke observes that the fear of crime that stops many people using public transport has a serious impact on revenues [11]. Furthermore, Cozens et al. [12] argue that there is significant potential to increase the use of public transport by making passengers feel safer and observe that risk perception discourages from using public transport. Beirão and Cabral [13] describe some key factors influencing modal choice, underlining the importance of attitude towards transport and differences in transit perception between users and non-users. Also noteworthy is a recent survey conducted in Netherlands in order to evaluate satisfaction with rail travel [14].

Measuring the impact of fear of crime is hence highly problematic and remains largely unexplored. However, it is very probable that individual characteristics (i.e. such as gender, disability, age and ethnicity) will also be variables worthy of further analysis that are not currently incorporated within usual interpretation of the cycle of fear.

\section{Questionnaire submitted and main findings of the study}

As previously written, the results presented in this paper are based on a questionnaire submitted to the students of IUAV University of Venice. The most part of them living out of Venice historical center, and being parking cost in the Lagoon normally beyond their means, Venetian students reach the University normally through public transport (normally by steamer, train or bus), walking the final part of their path. Because of this behavior, their average knowledge of transit modes in the Venetian area is generally high and they represent a good benchmark in analyzing public transport quality and its perception.

Students, aging between 21 and 24 years, were asked to describe both their usual journey behavior and feelings through a questionnaire composed of three parts (see table 1). The first one is related with the number and the nature of transport means used during a standard week. The second one is strictly connected with the risks perceived during both the outward and return journeys. The last one aims to identify solutions to perceived danger.

Quantitative analysis of the data obtained revealed that steamers and local trains are the transport modes mainly used from the respondents (fig. 1). Average time spent on board is rather variable: a good $50 \%$ of the interviewee lives however more than one hour away from the University (fig. 2).

There appears to be broad agreement between the respondents regarding the most part of the potential fear factors. Data analysis confirms mostly the results of Cozens et al., as far as both the influence of the sunlight on security enhancement and a higher perceived fear from the female respondents are concerned.

In detail: When waiting at transit stops, customers feel themselves in danger particularly after sunset. This tendency is extreme for the ladies, as shown from the comparison between the obtained night/day scores of 3.13 and 1.47 (both considered in a scale of 5 - see figure 3 ). 
Table 1: $\quad$ The questionnaire submitted.

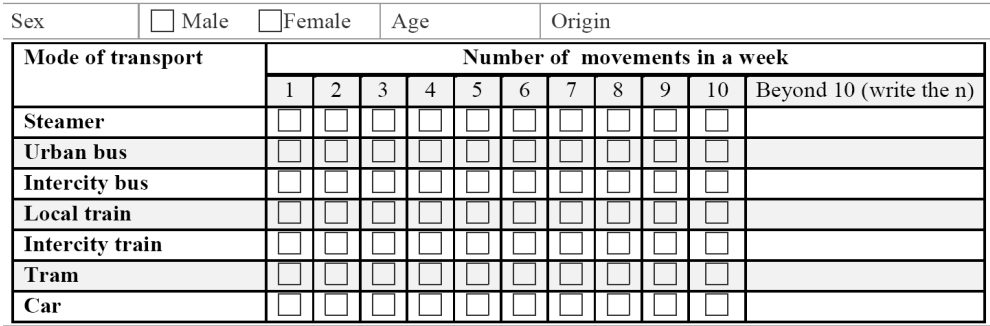

Average travel time $\quad \square$ 0-20 min $\square$ 21-45 min $\square$ 46-60 min $\square$ 1-1,5 h $\square$ 1,5-2 h $\square$ beyond 2h

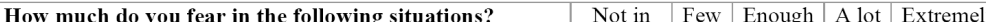

\begin{tabular}{|c|c|c|c|c|c|c|c|}
\hline \multicolumn{3}{|c|}{ now mucn do you rear in tie 10nowng situatons. } & the least & \multirow{2}{*}{$\square$} & Lifurthin & A & 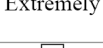 \\
\hline \multirow[t]{5}{*}{ Waiting at transit stop } & \multicolumn{2}{|l|}{ Alone during the day } & $\square$ & & $\square$ & $\square$ & $\square$ \\
\hline & \multicolumn{2}{|l|}{ With few people during the day } & $\bar{\square}$ & $\square$ & $\square$ & $\bar{\square}$ & $\square$ \\
\hline & \multicolumn{2}{|c|}{ With a lot of people during the day } & $\square$ & $\square$ & $\square$ & $\square$ & $\square$ \\
\hline & \multicolumn{2}{|c|}{ Alone after the sunset } & $\square$ & $\square$ & $\square$ & $\square$ & $\square$ \\
\hline & \multicolumn{2}{|l|}{ With few people after the sunset } & $\square$ & $\square$ & $\square$ & $\square$ & $\square$ \\
\hline \multirow[t]{6}{*}{ Approaching stops } & \multicolumn{2}{|l|}{ underpasses } & $\square$ & $\square$ & $\square$ & $\square$ & $\square$ \\
\hline & \multicolumn{2}{|l|}{ overpasses } & $\square$ & $\square$ & $\square$ & $\square$ & $\square$ \\
\hline & \multicolumn{2}{|l|}{ Alone during the day } & $\square$ & $\square$ & $\square$ & $\square$ & $\square$ \\
\hline & \multicolumn{2}{|l|}{ With few people during the day } & $\square$ & $\square$ & $\square$ & $\square$ & $\square$ \\
\hline & \multicolumn{2}{|l|}{ Alone after the sunset } & $\square$ & $\square$ & $\square$ & $\square$ & $\square$ \\
\hline & \multicolumn{2}{|l|}{ With few people after the sunset } & $\square$ & $\square$ & $\square$ & $\square$ & $\square$ \\
\hline \multirow[t]{4}{*}{ In parking area } & \multicolumn{2}{|l|}{ Alone during the day } & $\square$ & $\square$ & $\square$ & $\square$ & $\square$ \\
\hline & \multicolumn{2}{|l|}{ With few people during the day } & $\square$ & $\square$ & $\square$ & $\square$ & $\square$ \\
\hline & \multicolumn{2}{|l|}{ Alone after the sunset } & $\square$ & $\square$ & $\square$ & $\square$ & $\square$ \\
\hline & \multicolumn{2}{|l|}{ With few people after the sunset } & $\square$ & $\square$ & $\square$ & $\square$ & $\square$ \\
\hline \multirow[t]{5}{*}{ On board } & Alone during the day & & $\square$ & $\square$ & $\square$ & $\square$ & $\square$ \\
\hline & With few people during the da & & $\square$ & $\square$ & $\square$ & $\square$ & $\square$ \\
\hline & With a lot of people during the & day & $\square$ & $\square$ & $\square$ & $\square$ & $\square$ \\
\hline & Alone after the sunset & & $\square$ & $\square$ & $\square$ & $\square$ & $\square$ \\
\hline & With few people after the suns & & $\square$ & $\square$ & $\square$ & $\square$ & $\square$ \\
\hline Self service ticketing & Alone during the day & & $\square$ & $\square$ & $\square$ & $\square$ & $\square$ \\
\hline & With few people during the da & & $\square$ & $\square$ & $\square$ & $\square$ & $\square$ \\
\hline & Alone after the sunset & & $\square$ & $\square$ & $\square$ & $\square$ & $\square$ \\
\hline & With few people after the suns & & $\square$ & $\square$ & $\square$ & $\square$ & $\square$ \\
\hline $\begin{array}{l}\text { Does one of the follov } \\
\text { solutions improve you }\end{array}$ & $\begin{array}{l}\text { ing } \\
\text { r safe felling? }\end{array}$ & Not i & the least & Few & Enough & A lot & Extremely \\
\hline More lighting at travel & stops & & $\square$ & $\square$ & $\square$ & $\square$ & $\square$ \\
\hline More lighting at imme & liate access routes & & $\square$ & $\square$ & $\square$ & $\square$ & $\square$ \\
\hline More lighting in under & ass, overpass or parking area & & $\square$ & $\square$ & $\square$ & $\square$ & $\square$ \\
\hline CCTV & & & $\square$ & $\square$ & $\square$ & $\square$ & $\square$ \\
\hline More security staff & & & $\square$ & $\square$ & $\square$ & $\square$ & $\square$ \\
\hline Transparent shelter & & & $\square$ & $\square$ & $\square$ & $\square$ & $\square$ \\
\hline Shops close to travel s & & & $\square$ & $\square$ & $\square$ & $\square$ & $\square$ \\
\hline More open view & & & $\square$ & $\square$ & $\square$ & $\square$ & $\square$ \\
\hline More stops cleanliness & & & $\square$ & $\square$ & $\square$ & $\square$ & $\square$ \\
\hline Overpass instead of un & derpass & & $\square$ & $\square$ & $\square$ & $\square$ & $\square$ \\
\hline Real time information & & & $\square$ & $\square$ & $\square$ & $\square$ & $\square$ \\
\hline High reliability system & & & $\square$ & $\square$ & $\square$ & $\square$ & $\square$ \\
\hline Help buttons & & & $\square$ & $\square$ & $\square$ & $\square$ & $\square$ \\
\hline Coordination among $\mathrm{n}$ & odes & & $\square$ & $\square$ & $\square$ & $\square$ & $\square$ \\
\hline
\end{tabular}

Do conditions exist in which you choose NOT to use public transport because of unsafe perception? 


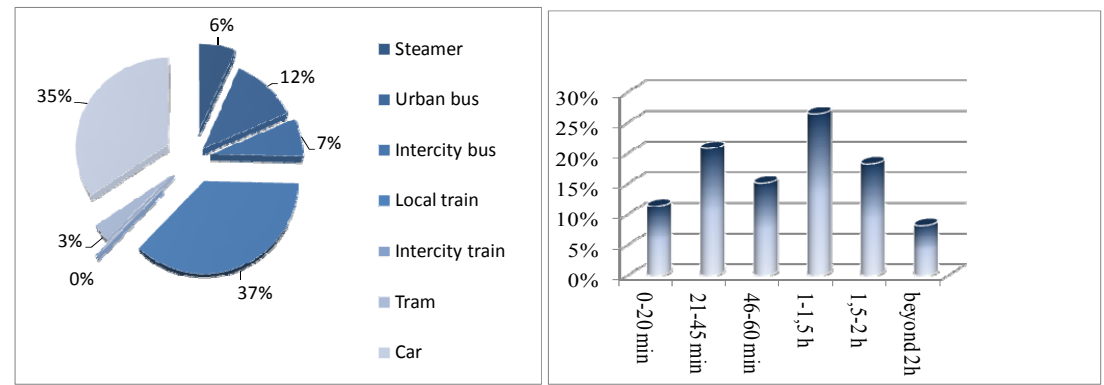

Figure 1: Transport modes used Figure 2: Journey duration of from the respondents. the respondents.

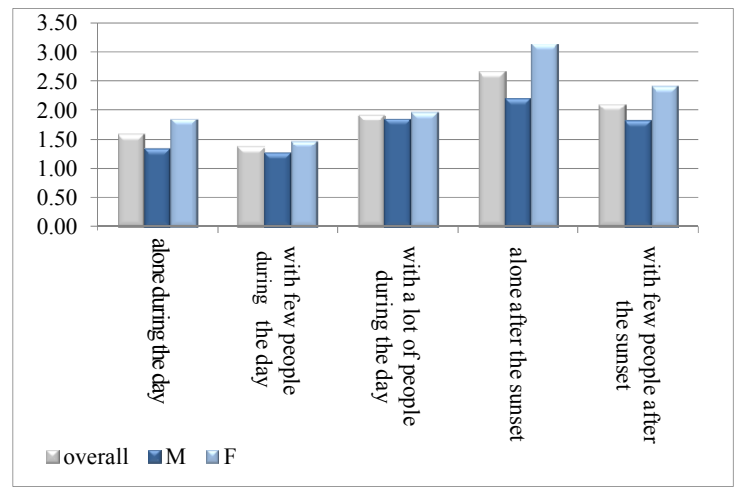

Figure 3: $\quad$ Perceived sense of danger while waiting at transit stops.

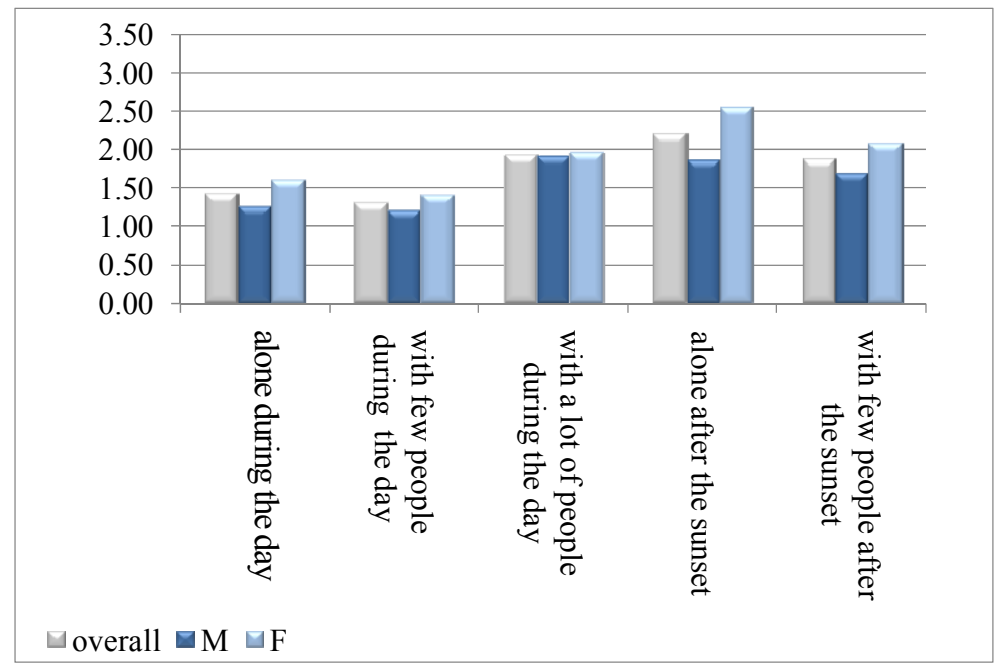

Figure 4: $\quad$ Fears on board. 
Scores expressed in relation to on board anxiety are rather constant and generally around 1.50-2.00 (figure 4). When approaching transit stops, fear peaks are mostly linked to underpasses, and people generally do not like to close in on transit stations alone after sunset (figure 5 - both).

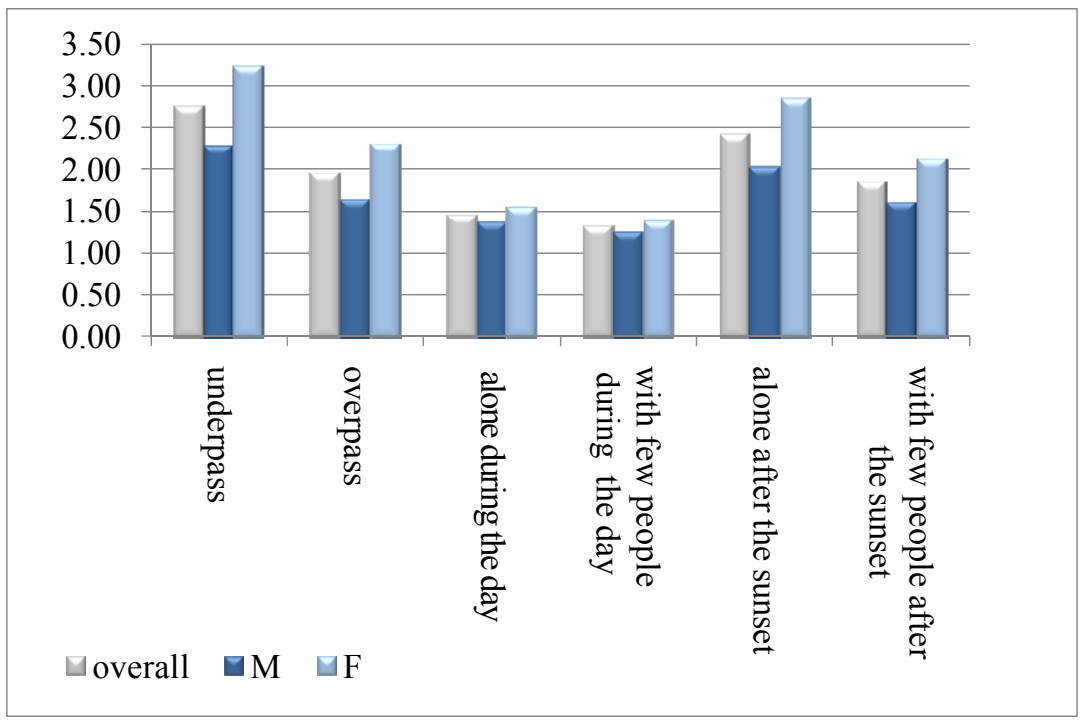

Figure 5: $\quad$ Fears in paths approaching stops.

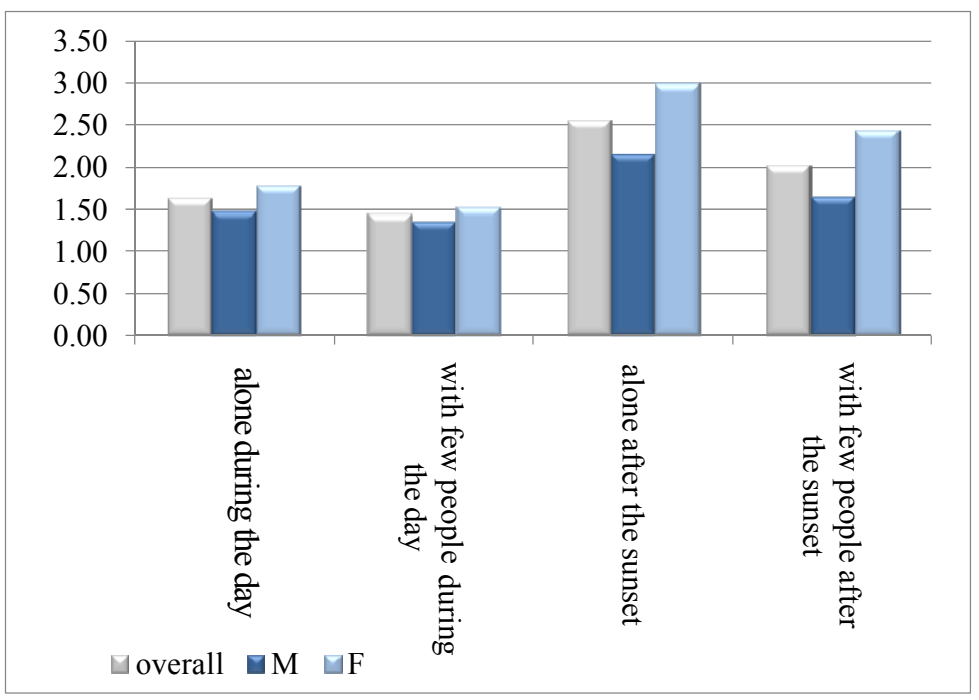

Figure 6: $\quad$ Fears in parking areas. 
Light presence is welcome also when using car parks at night (figure 6). Selfservice ticketing was the only main difference in the comparison between our results and the ones deriving from the South Wales case study [12]. Our respondents showed low anxiety in self booking (figure 7), because they generally do not get tickets after sunset, the most part holding a transit pass or buying a return ticket in the morning.

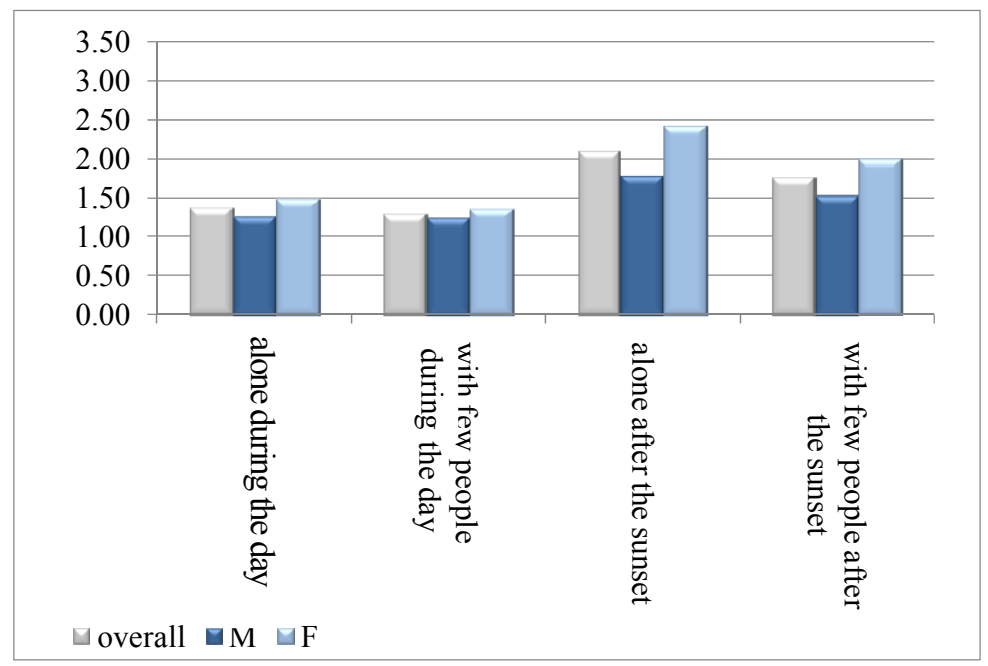

Figure 7: Fears in self service ticketing.

As shown from the previous figures, even if personal safety anxiety is different in its extent between the respondents of both genders, it is generally much lower during the day. A rough gender comparison shows that ladies exhibited far higher personal security concerns while approaching the transit stops via underpasses (at a score of 3.24 vs. the 2.28 recorded from the male respondents, figure 5$)$ or after sunset (2.85 vs. 2.02 , figure 5$)$. Similarly, as reported in figure 3 , when waiting for traffic means at night (3.13), they seem to be much more fearful than the gentlemen (2.20).

Male respondents expressed their highest level of fears across underpasses (2.28, figure 5), while also fearing for their personal safety while waiting alone at transit stop after sunset (2.20, figure 3) or when using the car park at night (2.15, figure 6).

An overall comparison of the figures 3-7 shows that the average difference in the perceived evaluations between night and day is more or less steady around a factor of 1 in a scale of 5 .

As far as possible interventions for enhancing perceived security are concerned, all the measures proposed in the questionnaire were generally considered effective, obtaining an average score higher than 2.50/5.00 (figure 8). 


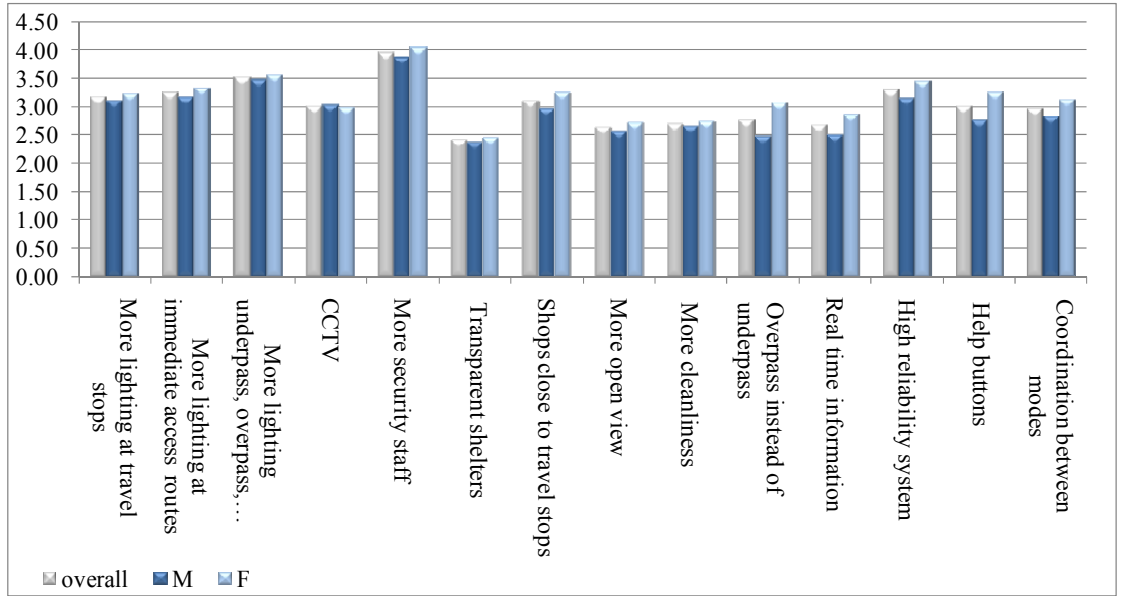

Figure 8: Improvement suggestions.

However, staff presence is by far considered the most successful measure, scoring an impressive 3.95. Highly appreciated from the respondents of both genders is also the presence of adequate lighting (3.50), as well as a high reliability system (3.29). These results may be useful in order to pick out improvements on public transit systems, as a higher quality perceived normally enhances transit modal share $[15,16]$.

Moreover, significant differences emerged from the comparison of single lines (figures 9, 10 and 11). Treviso line obtained the highest scores in the most part of the parameters investigated, mainly because of the presence of long underpasses and poorly floodlit parking areas.

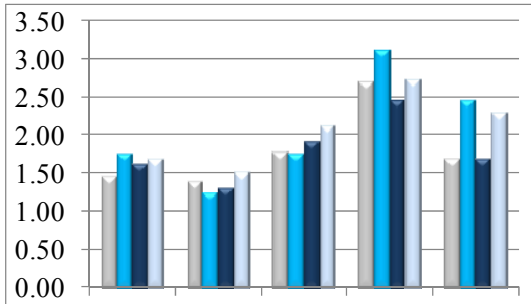

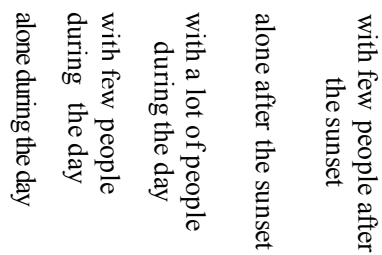

$\triangle$ Trieste $\square$ Treviso $\square$ Castelfranco $\triangle$ Padua

Figure 9: Fears while waiting.

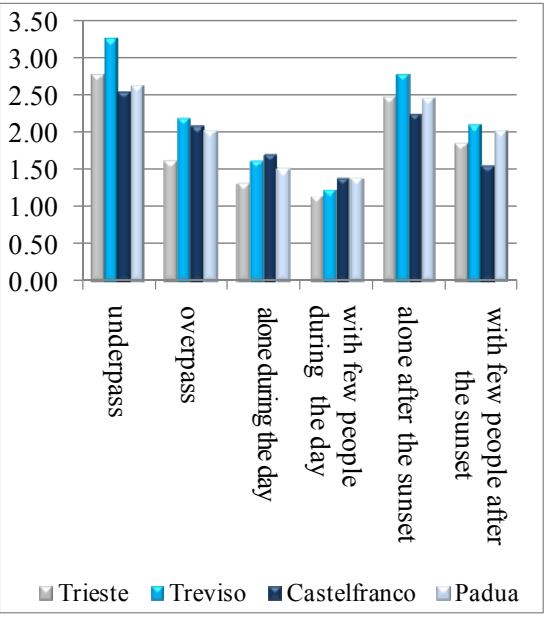

Figure 10: Fears in approaching stops. 

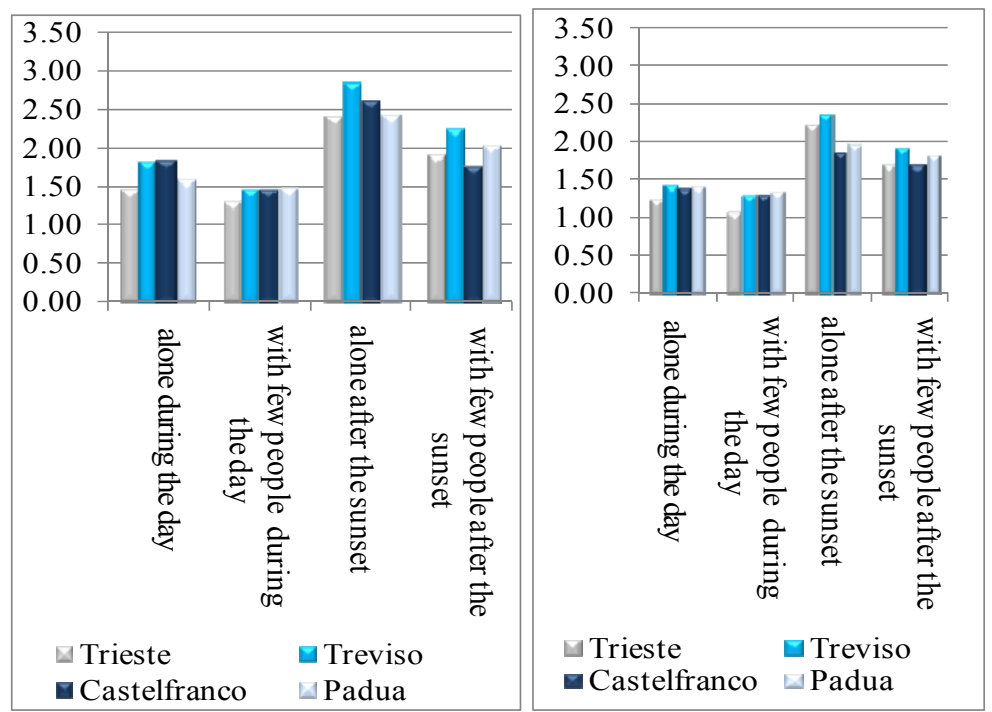

Figure 11: $\quad$ Fears in parking area (a) in self service ticketing (b).

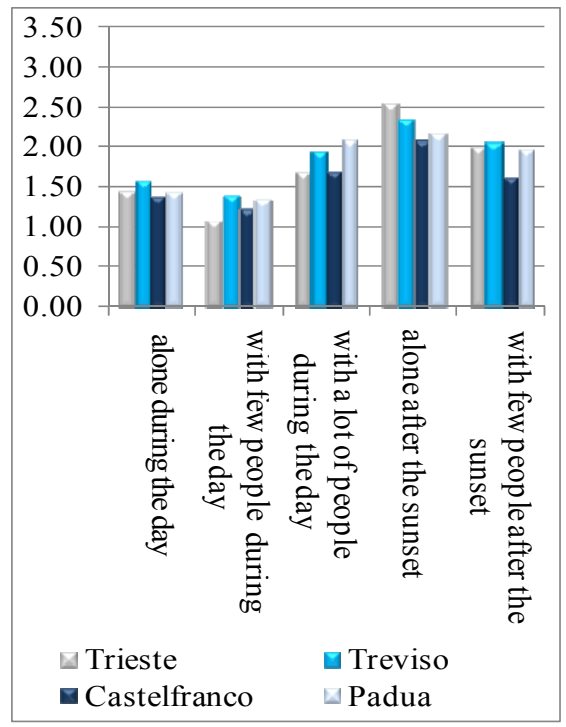

Figure 12: Fears on board.

Low scores for on-board parameters after sunset on the Trieste line should be linked to its low night demand. The Padua line shows the highest on-board score (2.08) during the day. This line seems however to require some improvement during peak hours, when overcrowding increases passenger feelings of 
insecurity. Furthermore, other interventions should be planned to help passengers to master dread after sunset both when waiting for the train and in approaching stations.

The Castelfranco line recorded higher average scores both in approaching stops and in parking areas during the day (figures 10,11 and 12), mostly why the most part of its travel stops are quite isolated, being neither close to private housing estates nor to commercial activities. A better design would be needed to connect those stops into the urban fabric.

\section{Conclusions}

Possible improvements in transit services are particularly important for transportation planning. By providing an attractive travel alternative, public transport cuts the price needed to reduce traffic congestion, benefiting the whole community. However, it is sometimes neglected from potential users because of discontent with its performance.

One of the main causes of discomfort from the passengers is the lack of perceived security, whose weighting for a class of low elasticity travel demand (i.e., University students) was the main objective of this study. Results reveal that measures to reduce potential threats for personal security in both transit stops and their immediate access are normally significantly appreciated from the users. Even if a more extensive, longer-term study is certainly necessary to verify these preliminary findings, the approach adopted and the results obtained so far seem encouraging.

Particularly, it was here observed that the presence of light seems to reduce the sense of fear considerably: after sunset, users generally fear walking through underground passages (this is the most feared feature at a score of 2.75/5.00), do not like to wait for traffic means of any kind (2.65) nor to approach bus stops or railway platforms (2.43). Significant perceived dread was also felt when using car park after sunset (2.55) and on-board (2.19).

In certain circumstances, the respondents clearly exhibited worries for their personal safety in relation to the transit stops and immediate access routes. As expected, female respondents exhibited higher levels of anxiety than the male. Female main concerns about their personal safety are while approaching transit stops and while waiting for transport means. Male respondents identified potential critical situations in walking across underground passes and using car parks at night.

All respondents generally preferred railway stations that were staffed. Generally the perceived security enhances consistently when the users feel that others are observing them: presence of other customers and closed-circuit television (CCTV) are generally appreciated.

These last remarks seem to call for the solitude as the main enemy to be fought in the process of a security-friendly public transport system. This is generally overlooked from conventional transportation planning, resulting in an increased vehicle travel and in withdrawing from potential health benefits deriving from shifts to less pollutant modes. 
Raising the priority of passenger perceptions in transportation planning should on the contrary provide a more balanced transportation system and may be a cost-effective way to improve its sustainability.

\section{References}

[1] Brantingham P.J., Brangtingham P.L., Wong, P.S. (1991): How public transit feeds private crime: notes on the Vancouver "Skytrain", experience. Security Journal 2 (2), 91-95.

[2] Grabosky, P., James, M. (1995): The Promise of Crime Prevention: Leading Crime Prevention Programs. Australian Institute of Criminology.

[3] Gaylord, M.S., Galliher, J.F. (1991): Riding the underground dragon: crime control and public order on Hong Kong's Mass Transit System. British Journal of Criminology 31 (1), 15-26.

[4] La Vigne, N.G., (1997). Visibility and vigilance: metro's situational approach to preventing subway crime. National Institute of JusticeResearch in Brief, US Department of Justice

[5] Collins, M. (1993). Strathclyde PTE focuses on safety of women passengers. Modern Railways 50 (534), 141.

[6] Sullivan, J.P. (1996). Transport crime and order maintenance: a North American perspective. Transit Policing March, 37-41.

[7] Parliamentary Travel Safe Committee (1998). Brisbane's city train network - part_-passenger security. Report No. 24, Legislative Assembly of Queensland.

[8] Eck, J.E. (1997). Preventing crime at places. In: Sherman, L.W., Gottfredson, D., MacKenzie, D., Eck, J., Reuter, P., Bushway, S. (Eds.), Preventing Crime: What Works, What Doesn't, What's Promising. A Report to the United States Congress, Prepared for the National Institute of Justice (Chapter 7)

[9] Nocera S., Tsakarestos A. (2004): Demand responsive transport systems for rural areas in Germany - an overview of the projects MOBINET and $\mathrm{MOB}^{2}$. Traffic Engineering \& Control, 45-10: 378-383

[10] Maguire, M., (1997). Crime statistics, pattern and trends: changing perceptions and their implications. In: Maguire, M., Morgan, R., Reiner, R. (Eds.), The Oxford Handbook of Criminology. Clarendon Press, pp. 135188.

[11] Clarke, R.V.G. (1996). Editorial introduction: crime and the economics of mass transit. In: Clarke, (Ed.), Preventing Mass Transit Crime. In: Crime Prevention Studies, vol. 6. Willow Tree Press, New York, pp. 1-4.

[12] Cozens P., Neale R., Whitaker J., Hiller D. (2003): Managing crime and the fear of crime at railway stations - a case study in South Wales (UK), International Journal of Transport Management 1. Pp. 121-132.

[13] Beirão G, Cabral J.A.S. (2007) Understanding attitudes towards public transport and private car: a qualitative study, Transport Policy 12, pp. 478489. 
[14] Givoni M., Rietveld P. (2007), The access journey to the railway station and its role in passengers' satisfaction with rail travel, Transport Policy 14, pp. 357-365.

[15] Nocera S. (2010). Un approccio operativo per la valutazione della qualità nei servizi di trasporto pubblico/An Operational Approach for Quality Evaluation in Public Transport Services. Ingegneria Ferroviaria 65-4: 363383.

[16] Nocera S. (2011). The Role of Quality Assessment in Public Transport Policy. Traffic Engineering \& Control 52-9: 394-398. 